\title{
Heavy metals removal by thiol modified oak charcoal: adsorption efficiency and selectivity
}

\author{
Zeinab Ezzeddine', Batoul Solh², Hussein Hamad ${ }^{3}$ \\ ${ }^{1,3}$ Department of Chemistry, Faculty of Science, Lebanese University, Lebanon \\ ${ }^{2}$ Platform for Research and Analysis in Environmental Sciences, Lebanese University, Lebanon
}

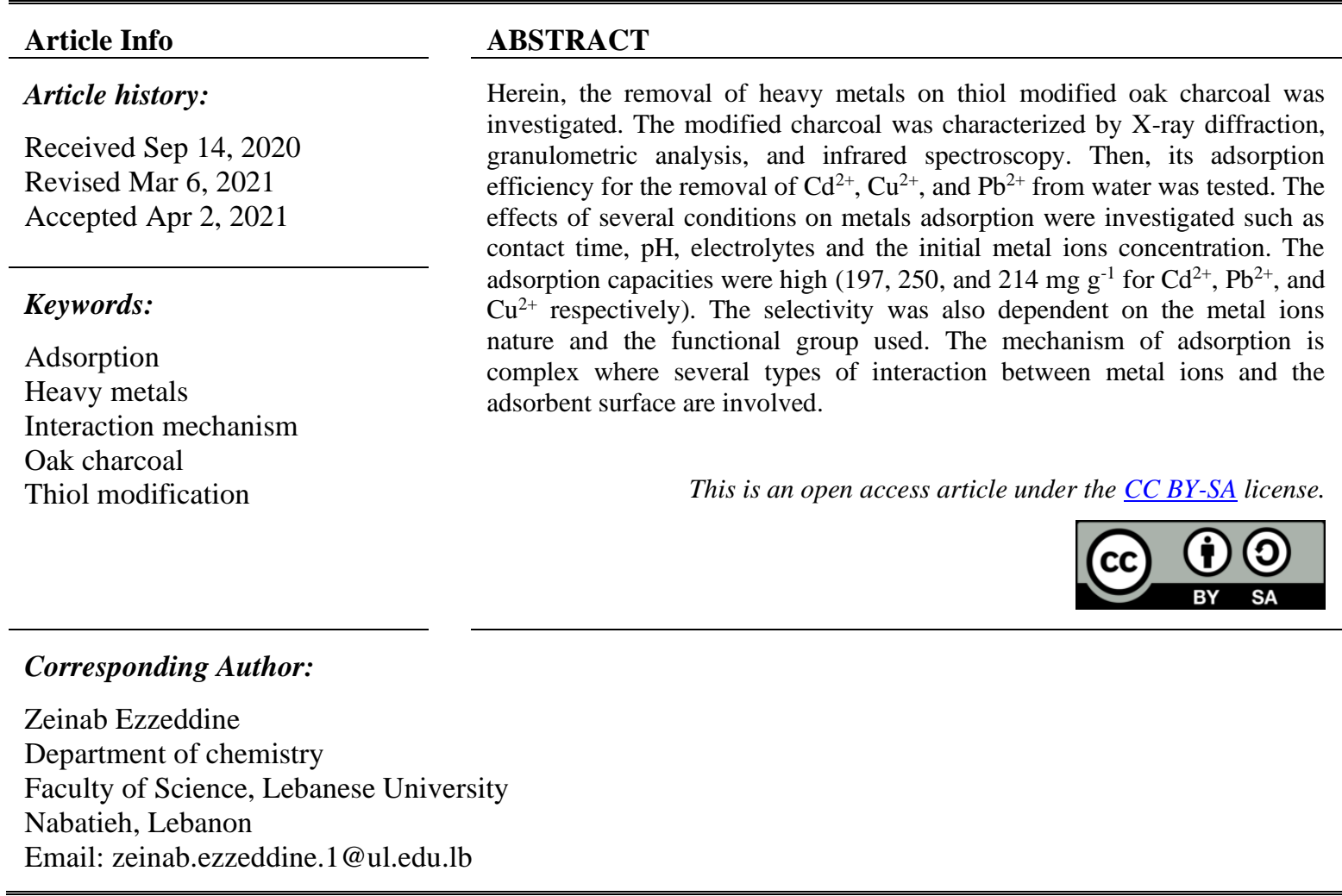

\section{INTRODUCTION}

Heavy metals are among the most dangerous pollutants discharged into the environment every day. They are persistent in nature and have accumulation tendcy in living organisms [1]. $\mathrm{Cu}^{2+}, \mathrm{Cd}^{2+}, \mathrm{and}^{\mathrm{Pb}^{2+}}$ are usually present in wastewater. Although these metals are essential for life in small amounts, the exposure of high levels can lead to serious health problems [2]. Many techniques are available for heavy metals removal from water, but adsorption is attracting a great deal of attention due to its simplicity and versatility [3]. Carbonaceous materials have been widely applied for waste water treatment since they have large surface area and can remove several types of contaminants [4]. Many researchers noted the effectiveness of modified activated carbon (AC) in heavy metals adsorption [5]-[7]. More research on activated carbon is still needed to better understand the performance towards certain contaminants and thus to enhance their removal from of wastewater.

Modifying AC surface by oxidizing agents is a widly used [8], but this technique tends to decrease the surface area of AC [9] so alternative methods were investigated to increase the removal of heavy metals without affecting the carbon structure such as modification with organic ligands [4]. Moreover, investigating the mechanism of adsorption is crucial for the synthesis of selective adsorbents with elevated properties for specific applications in liquid phase. Understanding the mechanism of metal ions binding is essential for describing and predicting the adsorption operation. The function of a specific surface group is important in fabricating novel adsorbents with higher efficiency [10]. 
In this study, oak charcoal carbon was modified by 3-mercaptopropyl trimethoxysilane (MPTMS). This modification method is practical and inexpensive which favors its applicability. Then the adsorption capacity for $\mathrm{Cu}^{2+}, \mathrm{Cd}^{2+}$, and $\mathrm{Pb}^{2+}$ removal was studied in details. The effects of several parameters on the process of adsorption were performed, as contact time, solution $\mathrm{pH}$, the electrolyte effect and metal ions concentration. The kinetic data of adsorption experiments were studied by pseudo-first and pseudo-secondorder models. The isotherms were fitted by both Freundlich and Langmuir. Moreover, the selectivity was studied as well in a ternary ions mixture.

\section{RESEARCH METHOD}

\subsection{Chemicals}

The 3-MPTMS, hydrochloric acid $(\mathrm{HCl}, 37 \%)$, sodium hydroxide $(\mathrm{NaOH})$, toluene and cadmium chloride $\left(\mathrm{CdCl}_{2} \cdot \mathrm{H}_{2} \mathrm{O} ; 93 \%\right)$ were purchased from Sigma Aldrich, while lead nitrate $\left(\mathrm{Pb}\left(\mathrm{NO}_{3}\right)_{2} 99.9 \%\right)$ was purchased from UNICHEM. Copper nitrate $\left(\mathrm{Cu}\left(\mathrm{NO}_{3}\right)_{2} .3 \mathrm{H}_{2} \mathrm{O}\right)$ from Alpha Chemika. All chemical reagents were used as received. Distilled water was produced in the laboratory.

\subsection{Activated carbon modification}

Commercially available oak charcoal was used (AC). Prior to usage, the carbon was grinded, washed with boiled distilled water and oven-dried at $120{ }^{\circ} \mathrm{C}$ for $24 \mathrm{~h}$. Then, $15 \mathrm{ml}$ MPTMS was added to 50 $\mathrm{g}$ of $\mathrm{AC}$ in $300 \mathrm{ml}$ toluene under magnetic stirring for $16 \mathrm{~h}$ at $200 \mathrm{rpm}$. After filtration, the resulting MPTMS-carbon was washed with $150 \mathrm{ml}$ toluene then dried at $150{ }^{\circ} \mathrm{C}$ for $4 \mathrm{~h}$. The obtained carbon was referred to as AC-SH as shown in Figure 1.

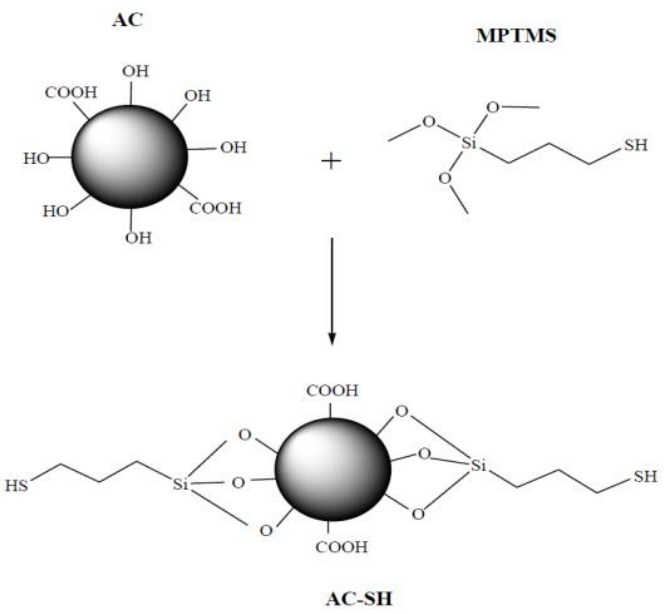

Figure 1. Modification of AC with MPTMS

\subsection{AC characterization}

The granulometric analysis that determines the size distribution after modification was conducted using Partica LA-950V2 Horiba. After modification, the functional groups were determined by Fourier Transform Infrared (FTIR) Spectroscopy in the range of $4000-400 \mathrm{~cm}^{-1}$. The carbon samples were blended with $\mathrm{KBr}$ then pressed into pellets and analyzed with FT-IR-6300 JASCO. X-ray diffraction was performed in the range of $2 \theta$ between $10^{\circ}$ and $60^{\circ}$ on a D8 Bruker diffractometer.

\subsection{Batch adsorption tests}

Different concentrations of metal ions solutions were prepared salts in distilled water from their corresponding. The solution $\mathrm{pH}$ was modified using $0.1 \mathrm{M} \mathrm{HCl}$ and $0.1 \mathrm{M} \mathrm{NaOH}$ solution. In typical batch studies, $0.1 \mathrm{~g}$ of the AC-SH was put in a beaker containing $50 \mathrm{~mL}$ of a metal solution of the desired concentration. The beaker was stirred at RT at $300 \mathrm{rpm}$ for $120 \mathrm{~min}$. After finishing each step, the solution was filtered and the metals concentration was detected for each metal using Atomic Adsorption Spectrophotometer (RAYLEIGH WFX-210). The metal ions adsorption percentage was calculated by (1) [11]. 


$$
R=\frac{\mathrm{C}_{0}-\mathrm{C}_{\mathrm{t}}}{\mathrm{C}_{0}} \times 100
$$

Where $\mathrm{R}$ is the adsorption rate $(\%), \mathrm{C}_{0}$ is the initial concentration and $\mathrm{C}_{\mathrm{t}}$ is the concentration at time $\mathrm{t}$. The adsorption capacity of the adsorbent at equilibrium was calculated by (2).

$$
\mathrm{q}_{\mathrm{e}}=\frac{\left(\mathrm{C}_{0}-\mathrm{C}_{\mathrm{e}}\right) V}{\mathrm{~m}}
$$

Where qe is the equilibrium adsorption capacity in $\mathrm{mg} \mathrm{g}^{-1}, \mathrm{C}_{0}$ is the initial concentration and $\mathrm{C}_{\mathrm{e}}$ is the concentration at equilibrium, $\mathrm{V}$ is the volume in $\mathrm{L}$ of metal solution and $\mathrm{m}$ is the mass in $\mathrm{g}$ of the adsorbent. For obtaining the isotherms, the batch experiments the initial metal ions concentrations were altered between $10 \mathrm{mg} \mathrm{L}^{-1}$ and $500 \mathrm{mg} \mathrm{L}^{-1}$. The solutions were then filtered by a $0.45 \mu \mathrm{m}$ syringe filter and the remaining metal ions were measured by AAS in order to calculate $\mathrm{C}_{\mathrm{e}}$ and $\mathrm{q}_{\mathrm{e}}$.

\section{RESULTS AND DISCUSSION}

\subsection{X-ray diffraction analysis and granulometric analysis}

Figure 2(a) shows the diffractograms of the activated carbon samples before and after MPTMS modification. As shown in the figure, the backbone of the $\mathrm{AC}$ was not affected by modification thus the structure was not altered by organic ligands anchoring. The size distribution of AC samples after modification are presented in Figure 2(b) a homogenous main particle distribution population was obtained with average diameter $19 \mu \mathrm{m}$.

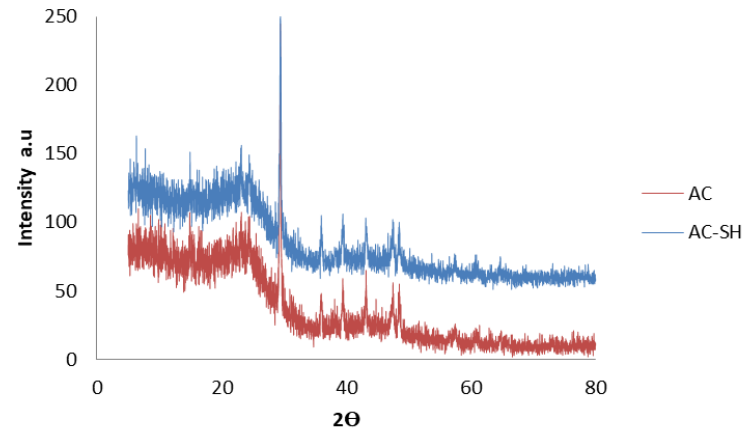

(a)

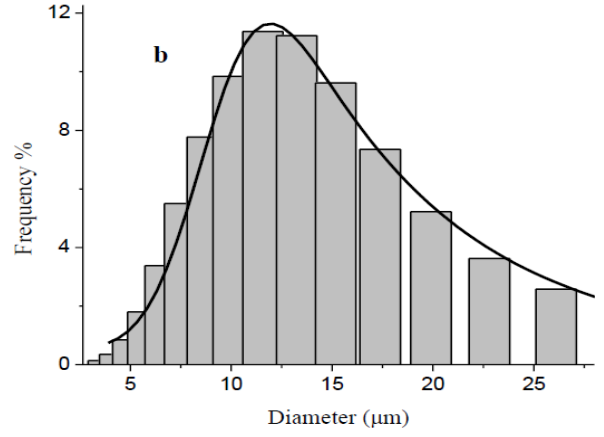

(b)

Figure 2. X-ray and granulometric analysis, (a) X-ray diffraction analysis of AC and AC-SH, (b) granulometric analysis of $\mathrm{AC}-\mathrm{SH}$

\subsection{FT-IR spectroscopy}

The modification of the AC surface was analyzed by FT-IR spectroscopy. The $\mathrm{S}-\mathrm{H}$ functional group frequencies were detected as shown in Figure 3. The broad band in the region $3300-3600 \mathrm{~cm}^{-1}$ in the AC and AC-SH spectra, is typically related to $-\mathrm{OH}$ stretching while the bands at $1439 \mathrm{~cm}^{-1}$ and $1750 \mathrm{~cm}^{-1}$ are characteristics of $-\mathrm{COOH}$ group. The peak at $2550 \mathrm{~cm}^{-1}$ correspondsto the thiol group [12]. The weak peaks at $2971 \mathrm{~cm}^{-1}$ and $2865 \mathrm{~cm}^{-1}$ belong to the stretching vibrations of $-\mathrm{C}-\mathrm{H}$ bonds [13]. The strong peak near $1054 \mathrm{~cm}^{-1}$ is due to $\mathrm{Si}-\mathrm{O}$ stretching vibrations [12]. The peaks around $1246 \mathrm{~cm}^{-1}$ and $693 \mathrm{~cm}^{-1}$ are characteristics of $\mathrm{Si}-\mathrm{O}-\mathrm{C}$ and $\mathrm{Si}-\mathrm{C}$ respectively.

\subsection{The pH effects}

Figure 4(a) shows the adsorption capacity of AC-SH as a function of $\mathrm{pH}$ which was varied between 2 and 8. At low $\mathrm{pH}$ values, adsorption decreased for the three metal ions due to the competition with $\mathrm{H}_{3} \mathrm{O}^{+}$ ions and the formation of positively charged moieties on the carbon surface (Figure 4(b)). As pH increased, adsorption increased and the maximum removal was reached between $\mathrm{pH} 5$ and 6 . At higher $\mathrm{pH}$ values, adsorption remained constant for lead and cadmium while it decreased for copper due to the formation of copper precipitate. So, the rest of the experiments were performed at $\mathrm{pH}=6$. 


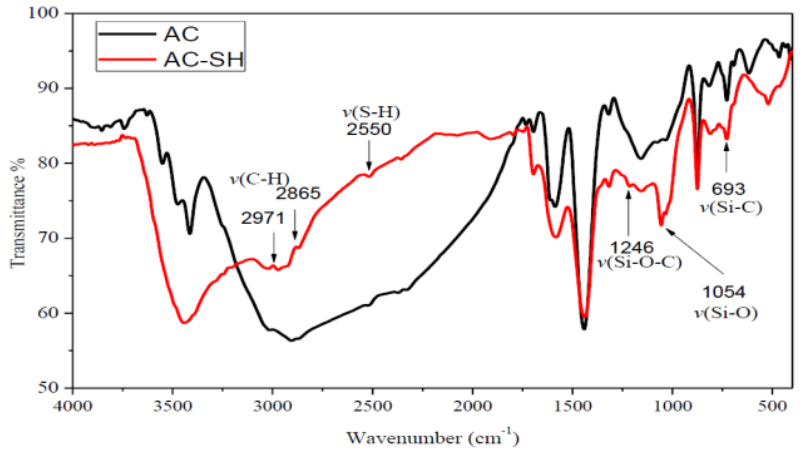

Figure 3. FT-IR analysis for carbon before and after modification with MPTMS

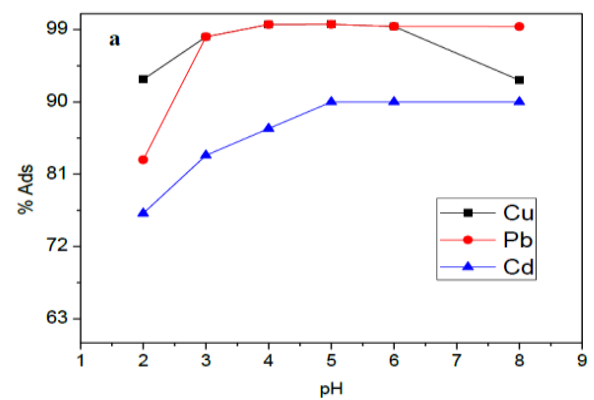

(a)
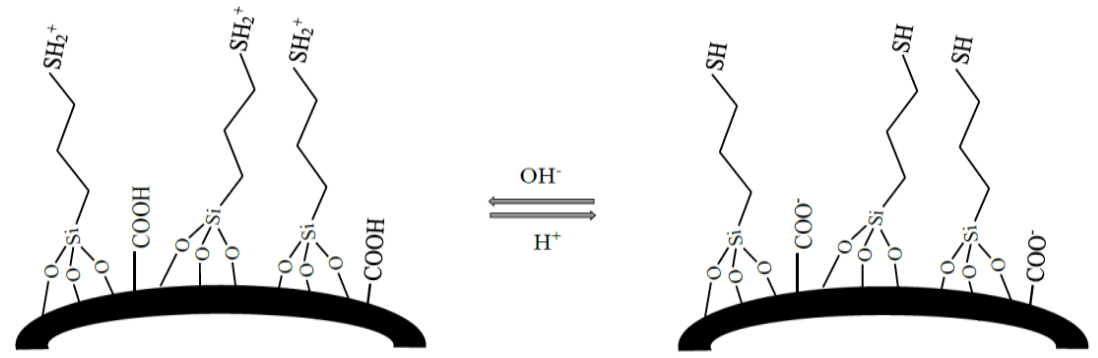

(b)

Figure 4. The pH effect: (a) metal ions adsorption and (b) on AC-SH surface

\subsection{Adsorption kinetic models}

\subsubsection{Pseudo-first order}

The pseudo first-order kinetic model is expressed as (3).

$$
\frac{d q_{t}}{d t}=k_{1}\left(q_{e}-q_{t}\right)
$$

Where qt and qe are the quantity of metal ions adsorbed $\left(\mathrm{mg} \mathrm{g}^{-1}\right)$ at time $\mathrm{t}(\mathrm{min})$ and at equilibrium respectively, and $\mathrm{k}_{1}$ is the rate constant of adsorption $\left(\mathrm{min}^{-1}\right)$. Integrating (3) with the following boundary conditions: $\mathrm{t}=0$ to $\mathrm{t}=\mathrm{t}$ and $\mathrm{qt}=0$ to $\mathrm{qt}=\mathrm{qt}$ yields $(4)$.

$$
\ln (\mathrm{qe}-\mathrm{qt})=\ln \mathrm{qe}-\mathrm{k}_{1} \mathrm{t}
$$

The plot of $\ln (\mathrm{qe}-\mathrm{qt})$ versus t should give a linear relationship where qe and $\mathrm{k} 1 \mathrm{can}$ be calculated from the plot intercept and slope respectively [14].

\subsubsection{Pseudo-second order}

The pseudo-second-order sorption rate is expressed in (5). 


$$
\frac{d q_{t}}{d t}=k_{2}\left(q_{e}-q_{t}\right)^{2}
$$

Where $k_{2}$ is the pseudo-second order rate constant $\left(\mathrm{g} \mathrm{mg}^{-1} \mathrm{~min}^{-1}\right), q_{\mathrm{t}}$ and $q_{\mathrm{e}}$ are the quantity of metal ions adsorbed at $\mathrm{t}$ time and at equilibrium $\left(\mathrm{mg} \mathrm{g}^{-1}\right)$ respectively. For the boundary conditions, $\mathrm{t}=0$ to $\mathrm{t}=\mathrm{t}$ and $q_{\mathrm{t}}=$ 0 to $q_{\mathrm{t}}=q_{\mathrm{t}}$, the integrated form of (6).

$$
\frac{\mathrm{t}}{\mathrm{q}_{\mathrm{t}}}=\frac{1}{k_{2} q_{e}^{2}}+\frac{t}{q_{e}}
$$

According to (6), a plot of $\mathrm{t} / q_{\mathrm{t}}$ versus $\mathrm{t}$ should yield a straight line from which $q_{e}$ and $k_{2}$ can be determined from the slope and intercept of the plot, respectively [15]. Metal ions adsorption as a function of contact time is illustrated in Figure 5(a). The kinetic parameters as well as the experimental equilibrium capacities are listed in Table 1. The obtained results revealed that $\mathrm{Cu}^{2+}, \mathrm{Cd}^{2+}$, and $\mathrm{Pb}^{2+}$ adsorption on $\mathrm{AC}-\mathrm{SH}$ followed the pseudo-second order kinetic model (Figure 5(b)). This suggests that the adsorption rate depends mainly on the content of active adsorption site on the adsorbent matrix.

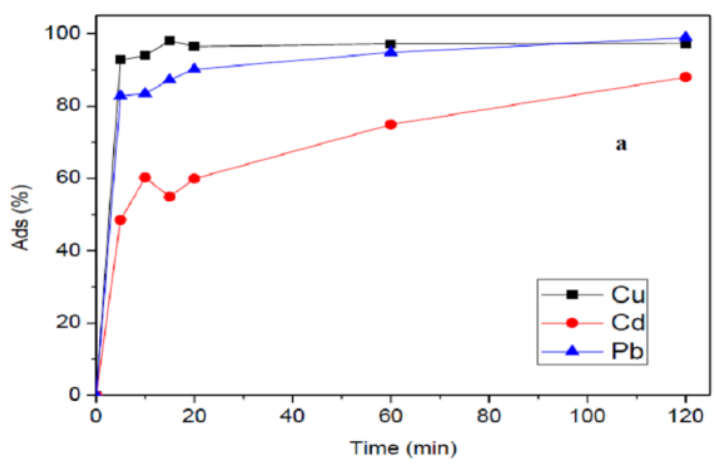

(a)

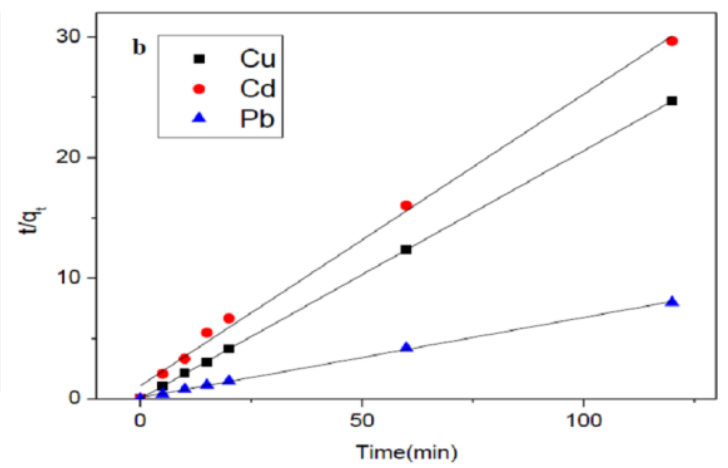

(b)

Figure 5. Contact time effect on metal ions adsorption: (a) pseudo-second order kinetic model and (b) $\left(\left[\mathrm{M}^{2+}\right]=0.14 \mathrm{mmol} \mathrm{L}-1, \mathrm{pH}=6\right.$ at $\left.\mathrm{RT}\right)$

\begin{tabular}{|c|c|c|c|c|c|c|c|}
\hline \multirow{3}{*}{\multicolumn{2}{|c|}{$\begin{array}{c}\mathrm{qe}^{\exp } \\
\left(\mathrm{mg} \mathrm{g}^{-1}\right)\end{array}$}} & \multicolumn{5}{|c|}{ AC-SH } & \\
\hline & & \multicolumn{3}{|c|}{ First order kinetic model } & \multicolumn{3}{|c|}{ Second order kinetic model } \\
\hline & & $\begin{array}{c}k_{1} \\
\left(\min ^{-1}\right)\end{array}$ & $\begin{array}{c}\mathrm{qe}^{\mathrm{cal}} \\
\left(\mathrm{mg} \mathrm{g}^{-1}\right)\end{array}$ & $\mathrm{R}^{2}$ & $\begin{array}{c}k_{2} \\
\left(\mathrm{~g} \mathrm{mg}^{-1} \min ^{-1}\right)\end{array}$ & $\begin{array}{c}\mathrm{qe}^{\mathrm{cal}} \\
\left(\mathrm{mg} \mathrm{g}^{-1}\right)\end{array}$ & $\mathrm{R}^{2}$ \\
\hline $\mathrm{Cu}^{2+}$ & 4.84 & 0.017 & 54 & 0.357 & 1.16 & 4.85 & 0.999 \\
\hline $\mathrm{Pb}^{2+}$ & 14.8 & 0.021 & 10 & 0.945 & 0.039 & 15 & 0.999 \\
\hline $\mathrm{Cd}^{2+}$ & 6.57 & 0.07 & 2.5 & 0.438 & 1.52 & 6.62 & 0.999 \\
\hline
\end{tabular}

Table 1. parameters of the two kinetic models

\subsection{Adsorption Isotherms}

\subsubsection{Langmuir isotherm model}

The model Langmuir Isotherm suggests a monolayer coverage of a finite number of identical sites present on the surface so that no more adsorption occur. Based on these assumptions, Langmuir represented (7) $[16]$.

$$
q_{e}=\frac{\mathrm{K}_{\mathrm{L}} \times q_{\max } C_{e}}{1+\mathrm{K}_{\mathrm{L}} C_{e}}
$$

Where $q_{\max }$ is the maximum adsorption capacity (monolayer coverage), i.e., mg of the adsorbate per $(\mathrm{g})$ of adsorbent and $\mathrm{K}_{\mathrm{L}}$ is Langmuir isotherm constant.

\subsubsection{Freundlich isotherm model}

This model explains a reversible and a non-ideal adsorption, not limited to monolayer formation. This model can be utilized for multilayer adsorption [17]. The equation is expressed as (8). 


$$
q_{e}=K_{f} C_{e}^{1 / n}
$$

Where $K_{f}$ is Freundlich isotherm constant $\left(\mathrm{mmol} \mathrm{g}^{-1}\right)$ and $\mathrm{n}$ is the adsorption intensity. The slope is a measure of surface heterogeneity and it ranges between 0 and 1 . If $n=1$ then the partition between the two phases is independent of the concentration. When the value of $\mathrm{n}$ decreases, the adsorbent surface heterogeneity increases. The value gets closer to zero when the system is more heterogeneous.

The obtained results for both models are presented in Figure 6 and their parameters are reported in Table 2. The values of $R^{2}$ for Langmuir model for $\mathrm{Pb}^{2+}$ were greatest while the $R^{2}$ values of Freundlich model for $\mathrm{Cu}^{2+}$ and $\mathrm{Cd}^{2+}$ were greatest. These obtained results proves that for $\mathrm{Pb}^{2+}$, Langmuir model fitted better while for $\mathrm{Cu}^{2+}$ and $\mathrm{Cd}^{2+}$ Freundlich model gave a better fit.
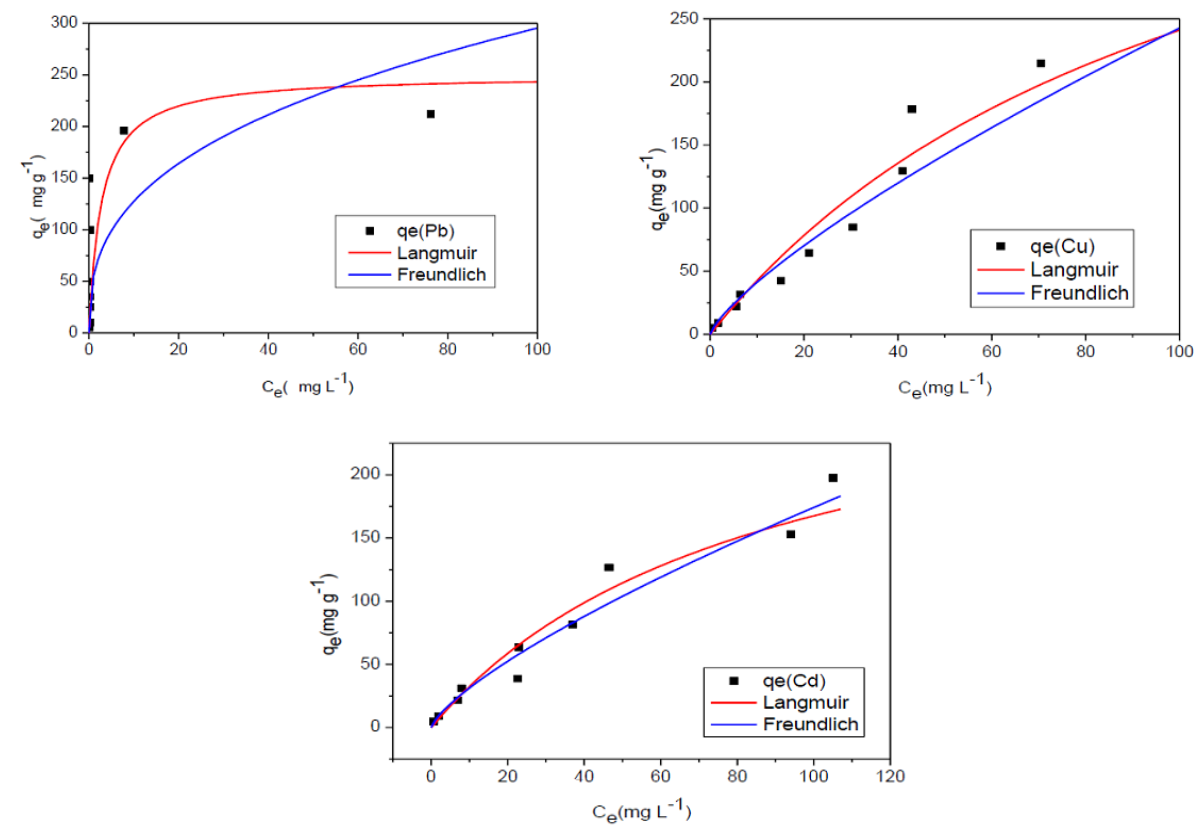

Figure 6. Freundlich and Langmuir models fit for $\mathrm{Pb}^{2+}, \mathrm{Cu}^{2+}$, and $\mathrm{Cd}^{2+}(\mathrm{pH}=6$ at $\mathrm{RT})$

Table 2. Comparison of Freundlich and Langmuir models for Me2+ removal by AC-SH

\begin{tabular}{|c|c|c|c|c|c|c|c|}
\hline \multirow[b]{2}{*}{$\mathrm{Me}^{2+}$} & \multirow[b]{2}{*}{$\begin{array}{c}q^{\exp } \\
\left(\mathrm{mg} \mathrm{g}^{-1}\right)\end{array}$} & \multicolumn{3}{|c|}{ Langmuir model } & \multicolumn{3}{|c|}{ Freundlich model } \\
\hline & & $\begin{array}{c}q^{\text {cal }} \\
\left(\mathrm{mg} \mathrm{g}^{-1}\right)\end{array}$ & $\begin{array}{l}\mathrm{K}_{\mathrm{L}} \\
\left(\mathrm{L} \mathrm{mg}^{-1}\right)\end{array}$ & $\mathrm{R}^{2}$ & $n$ & $\begin{array}{c}\mathrm{K}_{\mathrm{f}} \\
\left(\mathrm{mg} \mathrm{g}^{-1}\right)\end{array}$ & $\mathrm{R}^{2}$ \\
\hline $\mathrm{Cu}^{2+}$ & 214 & 199 & 0.01 & 0.742 & 1.29 & 7 & 0.972 \\
\hline $\mathrm{Pb}^{2+}$ & 250 & 242 & 0.3 & 0.988 & 2.73 & 55 & 0.339 \\
\hline $\mathrm{Cd}^{2+}$ & 197 & 171 & 0.012 & 0.578 & 1.34 & 5.61 & 0.979 \\
\hline
\end{tabular}

\subsection{Selectivity and effect of electrolytes \\ 3.6.1. Selectivity}

There were $0.1 \mathrm{~g} \mathrm{AC}-\mathrm{SH}$ added to $50 \mathrm{ml}$ of ternary ion solution of $\mathrm{Pb}^{2+}, \mathrm{Cd}^{2+}$, and $\mathrm{Cu}^{2+}$ of equimolar concentration. The sorption decrease in ternary metal ions solution compared to single metal ions may be attributed to the less availability of binding sites (Figure 7(a)). In ternary metal solution, the binding sites are divided competitively among the three ions. It was observed that $\mathrm{Pb}^{2+}$ has the highest adsorption capacity over $\mathrm{Cu}^{2+}$ and $\mathrm{Cd}^{2+}$ with respective rates of $90.9 \%, 88.6 \%$, and $86 \%$. The adsorption capacity of AC-SH in removing heavy metals from aqueous solution could be arranged in the following order: $\mathrm{Pb}^{2+}>\mathrm{Cu}^{2+}>\mathrm{Cd}^{2+}$.

In general, the sequence of adsorption capacity of heavy metals is largely dependent on physicochemical properties of metals. $\mathrm{Pb}^{2+}$ is preferentially adsorbed over $\mathrm{Cu}^{2+}$ and $\mathrm{Cd}^{2+}$ onto the binding sites of the AC-SH surface due to its high electronegativity (2.33) compared to that of $\mathrm{Cu}^{2+}$ and $\mathrm{Cd}^{2+}(1.9$ and 1.69 respectively). Moreover, thiol modified adsorbents were found to be more selective for $\mathrm{Pb}^{2+}$ more than other metal ions [18]. 


\subsubsection{Effect of electrolytes}

Generally speaking, the adsorption rate of the metal ion slightly decreases after changing the matrix electrolyte type. In the presence of $\mathrm{NaCl}$, the metal ions adsorption on $\mathrm{AC}-\mathrm{SH}$ decreased by $1 \%, 0.8 \%$ and $2.27 \%$ for $\mathrm{Pb}^{2+}, \mathrm{Cd}^{2+}$ and $\mathrm{Cu}^{2+}$ respectively. On the other hand, the presence of $\mathrm{KCl}$ affected the adsorption rate by $1.6 \%$ and $5.7 \%$ for $\mathrm{Pb}^{2+}$ and $\mathrm{Cd}^{2+}$ respectively while the removal of $\mathrm{Cu}$ (II) has not been affected (Figure 7(b)). This decrease is due to the fact that the existence of $\mathrm{NaCl}$ or $\mathrm{KCl}$ results in complexation of chloride and competition of sodium and potassium ions, with the metal ion to occupy some specific sites of the modified AC. This observation may be related to the formation of various complexes of metal ions with $\mathrm{Cl}^{-}$ligands (like $\mathrm{CdCl}_{2}, \mathrm{CdCl}_{3}^{-}, \mathrm{PbCl}_{4}^{2}$, etc.) where the $\mathrm{Cl}^{-}$ion may coordinate with metal ions and be treated as an inner sphere complex with the surface. Furthermore, the adsorption rate of the three studied metal ions in decreasing order: $\mathrm{Cu}^{2+}>\mathrm{Pb}^{2+}>\mathrm{Cd}^{2+}$ and this is linked directly to the affinity of the adsorbent towards each metal ion, the adsorption mechanism and the characteristics of each metal ion. AC-SH has lesser affinity towards $\mathrm{Cd}^{2+}$ that's why cadmium removal was affected the most in the presence of $\mathrm{NaCl}$ and $\mathrm{KCl}$.
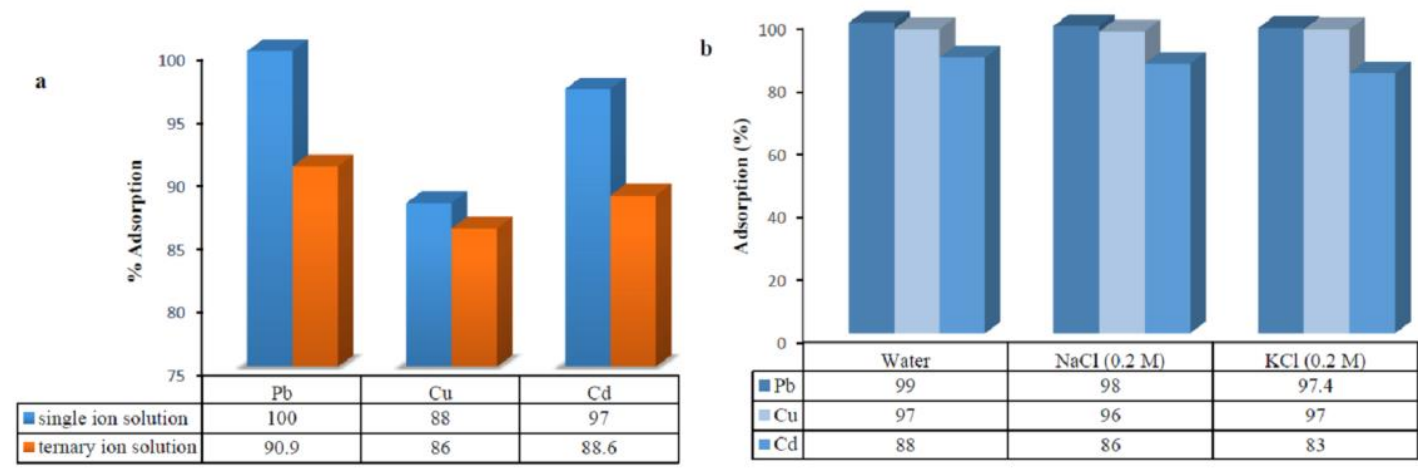

Figure 7. Selectivity of AC-SH, (a) a single and ternary ions solution and (b) electrolyte effect

\subsection{Adsorption mechanism}

The adsorption mechanism of heavy metals onto AC-SH is complicated and is a combination of electrostatic attraction and chemical interaction between the metal ions and the surface functional groups [19]. Nevertheless, the major adsorption mechanism is due chemical interaction (ions speciation as a function of $\mathrm{pH}$ ). AC-SH surface contains acidic groups besides the sulfer moieties. Carboxylic acid groups are responsible for the cation exchange capacity of carbon sorbents. Figure 8(a) illustrate the infrared spectra for AC-SH before and after metal ions adsorption. After metal complexing, the band characteristic for thiol group disappeared, which proves the interaction between - $\mathrm{SH}$ and metal ions. Also the band characteristic for carboxylic acid decreased significantly. These results verify the interaction of the sulfer groups and acidic groups found on the carbon surface with the metal ions during the adsorption process. A proposed schematic illustration is shown Figure 8(b).
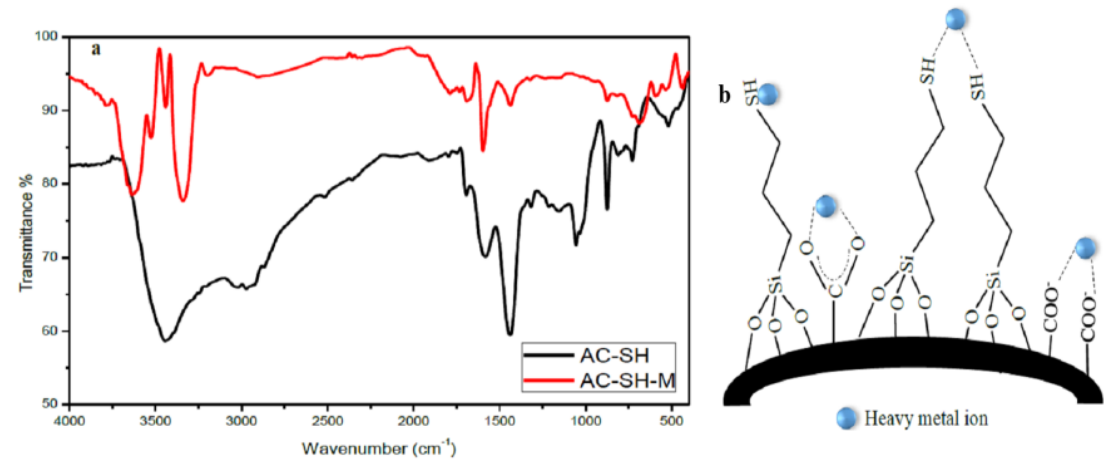

Figure 8. Infrared spectra for AC-SH, (a) before and after metal ions adsorption, (b) a proposed mechanism of adsorption on AC-SH 
The maximum adsorption capacities obtained in this study were found to be higher than those reported in the literature as shown in Table 3. This proves the efficiency of thiol modified oak charcoal for heavy metal ions from water.

Table 3. Adsorption capacities of several types of thiol modified adsorbents

\begin{tabular}{cccc}
\hline Adsorbent & Metal ion & $\mathrm{q}_{\max }\left(\mathrm{mg} \mathrm{g}^{-1}\right)$ & Ref \\
\hline Silica gel & $\mathrm{Cu}^{2+}$ & 186 & {$[20]$} \\
Nanoporous silica & $\mathrm{Hg}^{2+}$ & 118 & {$[21]$} \\
& $\mathrm{Cu}^{2+}$ & 89.5 & \\
Spent Grain & $\mathrm{Pb}^{2+}$ & 2099 & {$[22]$} \\
& $\mathrm{Zn}^{2+}$ & 227 & \\
SBA-16 & $\mathrm{Cd}^{2+}$ & 303 & \\
Mesoporous CMK-3 carbon & $\mathrm{Cu}^{2+}$ & 36 & {$[23]$} \\
& $\mathrm{Pb}^{2+}$ & 177 & {$[24]$} \\
& $\mathrm{Zn}^{2+}$ & 29 & \\
Oak charcoal & $\mathrm{Cu}^{2+}$ & 214 & \\
& $\mathrm{~Pb}^{2+}$ & 250 & This study \\
& $\mathrm{Cd}^{2+}$ & 197 & \\
\hline
\end{tabular}

\section{CONCLUSION}

In this study, oak charcoal was modified with thiol functional groups in order to be utilized as a heavy metals adsorbent. The modified carbon has proved to be effective in eliminating $\mathrm{Cd}^{2+}, \mathrm{Pb}^{2+}, \mathrm{and}^{2+}$ ions from water. The adsorption capacities were 197, 250, and $214 \mathrm{mg} \mathrm{g}^{-1}$ for $\mathrm{Cd}^{2+}, \mathrm{Pb}^{2+}$, and $\mathrm{Cu}^{2+}$ ions respectively. $\mathrm{pH}$ had the major effect on the adsorption capacity since it controls metal ions speciation in the solution as well as the surface charge. The process of adsorption obeys the pseudo second order kinetic model for all metal ions. The Freundlich model fitted better for $\mathrm{Cu}^{2+}$ and $\mathrm{Cd}^{2+}$ while Langmuir model gave a better fit for $\mathrm{Pb}^{2+}$. The adsorbent was selective for $\mathrm{Pb}^{2+}$. A mechanism of adsorption was proposed and it was found that both thiol moieties and carboxylic acid groups are involved in the adsorption process.

\section{REFERENCES}

[1] Hamad H, Ezzeddine Z, Lakis F, Rammal H, Srour M, Hijazi A., "An insight into the removal of $\mathrm{Cu}$ (II) and Pb (II) by aminopropylmodified mesoporous carbon CMK-3: Adsorption capacity and mechanism. Materials Chemistry and Physics, vol. 178, pp. 57-64, 2016, doi: 10.1016/j.matchemphys.2016.04.062.

[2] Dumrul H, Kursunlu AN, Kocyigit O, Guler E, Ertul S., "Adsorptive removal of $\mathrm{Cu}$ (II) and Ni(II) ions from aqueous media by chemical immobilization of three different aldehydes," Desalination, vol. 271, no. 1-3, pp. 92-99, 2011, doi: 10.1016/j.desal.2010.12.017.

[3] Chingombe P, Saha B, Wakeman RJ, "Surface modification and characterisation of a coal-based activated carbon," Carbon, vol. 43, no. 15, pp. 3132-3143, 2005, doi: 10.1016/j.carbon.2005.06.021.

[4] Hamad H, Ezzeddine Z, Kanaan S, Lakis F, Hijazi A, Moussawi MA., "A novel modification and selective route for the adsorption of $\mathrm{Pb}^{2+}$ by oak charcoal functionalized with glutaraldehyde," Advanced Powder Technology, vol. 27, no. 2, pp. 631-637, 2016, doi: 10.1016/j.apt.2016.02.019.

[5] Sato S, Yoshihara K, Moriyama K, Machida M, Tatsumoto H., "Influence of activated carbon surface acidity on adsorption of heavy metal ions and aromatics from aqueous solution," Applied Surface Science, vol. 253, no. 20, pp. 8554-8559,2007, doi: 10.1016/j.apsusc.2007.04.025.

[6] Zhu J, Yang J, Deng B., "Enhanced mercury ion adsorption by amine-modified activated carbon," Journal of Hazardous Materials, vol. 166, no. 2-3, pp. 866-872, 2009, doi: 10.1016/j.jhazmat.2008.11.095.

[7] Macias-Garcia A, Gomez-Serrano V, Alexandre-Franco MF, Valenzuela- Calahorro C, "Adsorption of cadmium by sulphur dioxide treated AC," Journal of Hazardous Materials, vol. 103, no. 1-2, pp. 141-152, 2003, doi: 10.1016/s0304-3894(03)00243-7.

[8] Li YH, Lee CW, Gullett BK., "Importance of AC's oxygen surface functional groups on elemental mercury adsorption," Fuel, vol. 82, no. 4, pp. 451-457, 2003, doi: 10.1016/S0016-2361(02)00307-1.

[9] Domingo-Garcia M, Lopez-Garzon FJ, Perez-Mendoza M., "Effect of some oxidation treatments on the textural characteristics and surface chemical nature of an activated carbon," Journal of Colloid and Interface Science, vol. 222, no. 2, pp. 233-240, 2000, doi: 10.1006/jcis.1999.6619.

[10] Puziya AM, Poddubnaya OI, Zaitsev VN, Konoplitska OP., "Modeling of heavy metal ion binding by phosphoric acid activated carbon," Applied Surface Science, vol. 221, no. 1-4, pp. 421-429, 2004, doi: 10.1016/S01694332(03)00956-5.

[11] Hadi M, Samarghandi MR, McKay G., "Equilibrium two-parameter isotherms of acid dyes sorption by activated carbons: study of residual errors," Chemical Engineerig Journal, vol. 160, no. 2, pp. 408-416, doi: 10.1016/j.cej.2010.03.016. 
[12] Tingaut P, Hauert R, Zimmermann T., "Highly efficient and straightforward functionalization of cellulose films with thiol-ene click chemistry," Journal of Materials Chemistry, vol. 21, no. 40, pp. 16066-16076, 2011, doi: 10.1039/C1JM11620G.

[13] McCarthy SA, Davies GL, Gun'ko YK., "Preparation of multifunctional nanoparticles and their assemblies," Nature Protocols, vol. 7, no. 9, pp. 1677-1693, 2012, doi: 10.1038/nprot.2012.082.

[14] Aguado J, Arsuaga J, Arencibia A, Lindo M, Gascón V., "Aqueous heavy metals removal by adsorption on aminefunctionalized mesoporous silica," Journal of Hazardous Materials, vol. 163, no. 1, pp. 213-221, 2009, doi: 10.1016/j.jhazmat.2008.06.080.

[15] Ezzeddine Z, Batonneau-Gener I, Pouilloux Y, Hamad H., "Removal of methylene blue by mesoporous CMK-3: Kinetics, isotherms and thermodynamics," Journal of Molecular Liquids, vol. 223, pp. 763-770, 2016, doi: 10.1016/j.molliq.2016.09.003.

[16] Langmuir I., "The constitution and fundamental properties of solids and liquids, Part I. Solids," Journal of American Chemical Society, vol. 38, no. 11, pp. 2221-2295, 1916, doi: 10.1021/ja02268a002.

[17] Freundlich HM., "Uber die adsorption in lo sungen," Journal of Physical Chemistry, vol. 57, no. 1, pp. 385-471, 1906, doi: 10.1515/zpch-1907-5723.

[18] Kang T, Park Y, Yi J., "Highly selective adsorption of $\mathrm{Pt}^{2+}$ and $\mathrm{Pd}^{2+}$ using thiolfunctionalized mesoporous silica," Industrial \& Engineering Chemistry Research, vol. 43, no. 6, pp. 1478-1484, 2004, doi: 10.1021/ie030590k.

[19] Machida M, Fotoohi B, Amamo Y, Ohba T, Kanoh H, Mercier L., "Cadmium (II) adsorption using functional mesoporous silica and activated carbon," Journal of Hazardous Materials, vol. 221-222, pp. 220-227, 2012, doi: 10.1016/j.jhazmat.2012.04.039.

[20] Najafi M, Rostamian R, Rafati AA., "Chemically modified silica gel with thiol group as an adsorbent for retention of some toxic soft metal ions from water and industrial effluent," Chemical Engineering Journal, vol. 168, no. 1, pp. 426-432, 2011, doi: 10.1016/j.cej.2010.12.064.

[21] Brown J, Mercier L, Pinnavaia TJ., "Selective adsorption of $\mathrm{Hg}^{2+}$ by thiolfunctionalized nanoporous silica," Chemical Communication, vol. 1, pp. 69-70, 1999, doi: 10.1039/A807249C.

[22] Chai L, Li Q, Zhu Y, Zhang Z, Wang Q, Wang Y, Yang Z., "Synthesis of thiol functionalized spent grain as a novel adsorbent for divalent metal ions," Bioresource Technology, vol. 101, no. 15, pp. 6269-6272, 2010, doi: 10.1016/j.biortech.2010.03.009.

[23] Xue X, Li F., "Removal of Cu (II) from aqueous solution by adsorption onto functionalized SBA-16 mesoporous silica," Microporous and Mesoporous Materials, vol. 116, no. 1-3, pp. 116-122, 2008, doi: 10.1016/j.micromeso.2008.03.023.

[24] Michalak-Zwierz K, Gdula K, Tyszczuk-Rotko K, Zawadzki W, Dąbrowski A, Barczak M., "Thiol-Functionalized Mesoporous Carbons as Adsorbents of Heavy-Metal Ions," Adsorption Science \& Technology, vol. 33, no. 6-8, pp. 663-6688, 2015, doi: 10.1260/0263-6174.33.6-8.663. 